\title{
UNA CONTRIBUCIÓN AL ESTUDIO DE LA HISTORIA RURAL DE MÉXICO
}

ENRIQUE FLORESCANO

Dirección de Proyectos Históricos del CONACULTA

JESÚS GÓMEZ SERRANO, Haciendas y ranchos de Aguascalientes. Estudio regional sobre la tenencia de la tierra y el desarrollo agrícola en el siglo XIX, México, Universidad Autónoma de Aguascalientes/Fomento Cultural Banamex, 2000, 516 pp.

Com omenzaré mi comentario resaltando lo que hoy parece obvio en la historia intelectual de Jesús Gómez

Serrano. En primer lugar que esta obra, Haciendas y ranchos de Aguascalientes, es la culminación de veinte años de investigación continua sobre la historia agraria de la región de Aguascalientes, como lo muestran algunos de sus anteriores libros y artículos: Ojocaliente: una hacienda devorada por la urbe, El mayorazgo de Rincón Gallardo, Hacendados y campesinos en Aguascalientes, "Los indios de Jesús María y su lucha por la tierra", "Los trabajadores agrícolas en la región de Aguascalientes en el siglo XIX", Aguascalientes en la historia, "El crédito agrícola en Aguascalientes", Ciénega de Mata, etc.

Haciendas y ranchos de Aguascalientes recoge esa larga experiencia de investigación de archivos y bibliotecas, integra temas, problemáticas y reflexiones teóricas sobre la historia agraria regional y nacional, y nos brinda una obra sólida, una aportación significativa sobre la formación de la grande y la mediana propiedad en esta región de nuestro país a lo largo de un siglo. Como el propio autor lo reconoce, la historia de la formación de la gran propiedad territorial ha sido un tema fascinante para muchas generaciones de estudiosos, comenzando por los clásicos de Wistano Luis Orozco, 
Andrés Molina Enríquez, Frank Tannenbaum y François Chevalier. Es un tema que en la segunda mitad del siglo que está por terminar tuvo un gran auge y produjo también una serie de obras innovadoras que cambiaron nuestra perspectiva sobre la historia agraria y el peso que la relación con la tierra ha tenido en la historia de México.

Estas obras recientes, al inclinarse por el análisis económico de la producción agrícola, al interesarse por los problemas de las técnicas, los mercados, el crédito, las inversiones y la rentabilidad de las unidades de producción, contribuyeron decisivamente a destruir la imagen negativa que se había forjado de la gran propiedad como latifundio improductivo, y abrieron nuevas vías para revalorar la propiedad agraria. En esta revaloración de la propiedad y la historia agraria se inscribe la obra de Jesús Gómez Serrano.

La novedad y el interés que tiene Haciendas y ranchos de Aguascalientes es que trata los temas clásicos de la historia agraria desde una perspectiva secular, el siglo XIX, con un enfoque regional. La gran propiedad es desde luego uno de los capítulos centrales, pero en este caso nos encontramos con un análisis del incremento de los sistemas de arrendamiento y mediería, y con estudios sobre el colapso de los sistemas de crédito y de la inestabilidad política, tres fenómenos que intervienen en la crisis y disminución de la gran hacienda.

Otro capítulo importante está dedicado a la pequeña propiedad y los pueblos de indios, dos aspectos íntimamente relacionados con la situación de la ciudad de Aguascalientes. El autor muestra que en el periodo 1821-1854 hay un robustecimiento de la pequeña propiedad y una desaparición progresiva de los pueblos de indios.

En el periodo de las grandes crisis políticas, entre 1854 y 1868 , hay un deterioro general de la economía que afecta a todas las actividades agrícolas, pero especialmente a la gran hacienda. La desamortización de las propiedades de la Iglesia y de las comunidades indígenas no produce los esperados beneficios en la economía ni crea la nación de los medianos y pequeños propietarios que postularon los liberales. En cambio, estos procesos sí continúan el fraccionamiento de las antiguas grandes propiedades y forman una nueva generación de propietarios de la tierra, que vienen de los negocios 
especulativos, del comercio, de la asociación del capital con el poder político y del ascendente grupo de rancheros.

En la segunda mitad del siglo, estos procesos se aceleran. Así, Jesús Gómez Serrano muestra a través de minuciosos estudios que entre 1868 y 1910 continúa el proceso de fragmentación de la gran propiedad. También observa los procesos de modernización en el riego, la maquinaria, los nuevos sistemas de crédito y la introducción de nuevos cultivos.

El autor muestra cómo el proceso de desintegración de la gran propiedad va acompañado por la aparición de una nueva generación de hacendados, más emprendedores y abiertos a los cambios, y por un crecimiento extraordinario del sistema de arrendamiento y de los medieros. Éstos son los nuevos protagonistas, junto con el grupo de los rancheros, del desarrollo agrícola de la segunda mitad del siglo XIX, así como sus beneficiarios. Los perdedores en este proceso de cambio fueron otra vez los indígenas.

De modo que a través de este escrupuloso y bien documentado estudio tenemos una nueva visión de la historia de la gran hacienda y del desarrollo agrícola de una región del centro-norte de México. Esta visión de largo alcance, que abarca todo un siglo, confirma lo que ya se había observado en otras regiones del país: la progresiva desintegración de la gran hacienda. En este proceso tan cuidadosamente documentado, sólo lamenté la ausencia de un análisis similar de los testamentos y de la fragmentación de la hacienda por vía de la herencia. Creo, asimismo, que hace falta complementar los datos económicos que se dan sobre los nuevos protagonistas (los nuevos hacendados, pero sobre todo los medieros y rancheros), con un análisis sobre sus bases sociales; es decir, como ejemplos representativos, en el caso de los medieros y los rancheros, de las nuevas clases medias. Debemos recordar que la identidad ranchera es uno de los aspectos más descuidados en la historia de la formación de las identidades mexicanas. El ascenso del grupo de los rancheros que se da por entonces en Aguascalientes, es un fenómeno muy extendido en Jalisco, Michoacán, la Huasteca Veracruzana y Potosina, y en otras regiones de México. Pero aún carecemos de buenos estudios demográficos y sociales que nos proporcionen nuevos 
datos sobre la formación de esa identidad ranchera, que a comienzos del siglo XX será uno de los rasgos característicos de la identidad mexicana.

También pienso que los temas que Jesús Gómez Serrano aborda en este libro están vinculados al gran tema de la formación de la identidad regional. Hay que recordar que el proyecto de Estado-nación que maduró en México en la segunda mitad del siglo XIX se impuso como primera tarea someter la diversidad de la nación a la unidad del Estado. Esta política, como sabemos, se tradujo en los hechos en una historiografía centralista que privilegiaba la unidad de la nación sobre las identidades locales, regionales y grupales. Es decir, la imposición del canon nacionalista significó el aplazamiento y el rebajamiento de la historia local, regional y grupal como temas fundamentales del desarrollo histórico de nuestro país. Así como el Estado-nación se propuso uniformar la lengua, la educación, la hacienda pública y la justicia, del mismo modo apoyó la construcción de una historiografía orientada a borrar el florecimiento de memorias locales y regionales.

Pienso que los estudios regionales como los que desde hace veinte años ha impulsado Jesús Gómez Serrano son la mejor respuesta al centralismo historiográfico que se resumió en el nacionalismo extremo del siglo $\mathrm{XX}$, intentando cerrar los ojos ante la verdadera diversidad y pluralidad de la nación. Una de las principales diversidades de la nación mexicana real es su diversidad regional, la existencia de profundas y arraigadas identidades regionales.

Hago votos porque esta obra excelente, y las muchas otras que se están produciendo en diversas regiones del país, nos den pronto nuevos libros sobre la identidad regional, sobre el sustento histórico, social y cultural que alienta a muchos millones de mexicanos. 